\title{
Exame Nacional do Ensino Médio: entre a regulação da qualidade do Ensino Médio e o vestibular
}

\section{National Examination of High School: between the adjustment of the quality of teaching and the vestibular system}

\author{
Jean Mac Cole Tavares Santos ${ }^{1}$
}

\begin{abstract}
RESUMO
Nosso artigo apresenta estudo sobre o Exame Nacional do Ensino Médio (ENEM) criado, em 1998, pelo Ministério da Educação (MEC) para avaliar as competências e habilidades desenvolvidas pelos alunos do Ensino Médio. Defendemos aqui, a partir de dados e documentos oficiais, de pesquisa com professores do ensino médio e de vasta bibliografia, que o ENEM nasce visando ser um instrumento governamental para forçar um currículo de base nacional, tentando a qualidade da educação via o instrumento avaliativo sendo, assim, reguladora da qualidade. A prova do $\mathrm{MEC}$, desde sua concepção, objetivava ser o instrumento para as mudanças curriculares no Ensino Médio de acordo com a concepção de um mundo em transformação, exigente de novas habilidades e competências. Inicia-se o processo de colocar o exame nacional em primeiro plano para corrigir e orientar os currículos das escolas médias criando novas demandas de conhecimento por meio da avaliação nacional. Sua função reguladora, no entanto, foi perdendo sentido na medida em que as escolas foram encontrando formas de preparar para o exame em momentos extra sala de aula. A competição descabida, entre escolas, entre instituições, entre redes de ensino tomou lugar. $\mathrm{O}$ treinamento para a realização da prova tirou o caráter inicial de regular a qualidade.
\end{abstract}

Palavras-chave: educação secundária; ENEM; currículo Ensino Médio.

1 Doutor em Educação pela Universidade Federal da Paraíba (UFPB).Professor Adjunto 2 da Faculdade de Educação da Universidade do Estado do Rio Grande do Norte (UERN). Coordenador do Laboratório de Estudos em Paulo Freire e Educação popular(LEFREIRE/FE), Brasil. 


\begin{abstract}
Our paper presents a study on the National Examination of High School Education created in 1998 by the MEC to assess the skills and abilities developed by High School students. We stand here, from data and official documents, research with high school teachers and extensive bibliography, that at first ENEM aimed to be an instrument of government to force a national core curriculum, trying to have the quality of education via the evaluation instrument being like this the regulation of quality. The evaluation system of MEC since its inception, aimed to be the instrument for curriculum changes in High School according to the concept of a changing world, demanding new skills and competencies. One begins the process of the first national exam as a way to correct and guide the curricula of middle schools by creating new demands for knowledge through the national evaluation. Its regulatory function, however, started missing its target when schools discovered ways to prepare for the exam in extra moments to the classroom. The senseless competition among schools, among institutions, among educational systems took place. The training for taking the exam ended the initial characteristics of regulation of quality.
\end{abstract}

Keywords: secondary education; ENEM; High School curriculum.

O Exame Nacional do Ensino Médio (ENEM) foi criado em 1998 pelo Ministério da Educação (MEC) para avaliar as competências e habilidades desenvolvidas pelos alunos que estão concluindo ou já concluíram o Ensino Médio. Ele é apresentado pelo MEC como auxiliar da escola para a construção do conhecimento do aluno.

$\mathrm{O}$ questionamento basilar, neste artigo, pretende entender como uma avaliação de caráter nacional poderia influenciar de forma positiva, na sala de aula, a ponto de poder ser considerada um auxiliar do professor na árdua tarefa de propiciar aos alunos um aprendizado consistente. Mais complicado fica, ainda, se consideradas as diferenças regionais, a grandeza territorial do Brasil e a flexibilidade curricular (mesmo que, depois, limitada por vários aspectos legais e reais), conquistada pelas escolas com a LDB de 1996 e confirmada pelas DCNEM. Para referendar a análise, foram utilizadas, além da leitura e interpretação das bases legais do Exame, entrevistas com professores e diretores com atuação no Ensino Médio em quatro escolas do interior do Ceará e em duas escolas do interior do Rio Grande do Norte. ${ }^{2}$

2 Os professores e diretores entrevistados participaram das pesquisas sobre as reformas do Ensino Médio nos estados do Ceará e do Rio Grande do Norte, realizadas pelo autor, com financiamento da Fundação Cearense de Apoio ao Desenvolvimento Científico e Tecnológico (FUNCAP) e pela Fundação de Apoio à Pesquisa do Rio Grande do Norte (FAPERN). 
A pretensão do ENEM era avaliar a qualidade do Ensino Médio ao mesmo tempo em que dava ao aluno, e somente a ele, já que os resultados são individuais e sigilosos, uma noção de suas qualidades e deficiências em face das competências para enfrentar o mundo. A prova procurava atingir quatro competências básicas, articulando conteúdos da vida cotidiana e conteúdos conceituais das diversas disciplinas, como: domínio de linguagens, compreensão de fenômenos, enfrentamento de situações-problema, construção de argumentações e elaboração de propostas de intervenção na realidade.

De forma geral, os objetivos do ENEM, divulgados pelo INEP - Instituto Nacional de Estudos e Pesquisas Educacionais Anísio Teixeira - para o ano de 1999 e ainda em vigor até a presente data, são assim apresentados:

I - Oferecer uma referência para que cada cidadão possa proceder à sua auto-avaliação com vistas às suas escolhas futuras, tanto em relação ao mercado de trabalho quanto em relação à continuidade de estudos;

II - estruturar uma avaliação ao final da educação básica que sirva como modalidade alternativa ou complementar aos processos de seleção nos diferentes setores do mercado de trabalho;

III - estruturar uma avaliação ao final da educação básica que sirva como modalidade alternativa ou complementar aos exames de acesso aos cursos profissionalizantes pós-médios e à Educação Superior. (www.inep.gov.br)

Desde seu lançamento, o ENEM guarda a intenção de ser mais do que simplesmente uma avaliação diagnóstica do quadro educacional brasileiro. Ele pretende se construir como uma avaliação que seja, ao mesmo tempo, de diagnóstico individual, possibilitando que o 'cidadão' faça suas escolhas de acordo com suas competências, e como uma avaliação com características complementares e (ou) substituta de outros exames existentes para admissão ao mercado de trabalho e (ou) pós-médios e superiores. O ENEM, nesse caso, já nasce como um projeto de ambição extremamente dilatada.

A ideia é confirmada por uma reportagem da Folha de S. Paulo, em julho de 1997 (TÓFOLI, 2007). Segundo a entrevista com o ministro da Educação sobre as propostas de reforma do ensino, o ENEM poderá servir de credenciamento dos alunos para as universidades, e as mudanças no currículo serão incorporadas ao Exame, contribuindo para melhorar o processo de seleção para seu ingresso no curso superior. Ele assevera que há uma determinação de mudar o sistema de entrada no ensino superior, e a LDB dá opção para que cada universidade fixe seu critério de ingresso, portanto o vestibular tradicional tem os seus dias contados. 
Todavia, não obstante um apoio de propaganda que incluía inserções em televisão, rádio, jornal e revista em todo o país e, mais ainda, um acirrado contato e a mobilização com as secretarias estaduais para fazerem o acompanhamento das inscrições junto às escolas, não houve retorno do número de participantes esperados pelo ministério nas primeiras edições do Exame. A opcionalidade na avaliação, isto é, o fato de não haver nenhum dispositivo que obrigasse os concluintes ou egressos do Ensino Médio a realizarem a prova, fez com que ela tivesse um começo aquém do idealizado. No primeiro exame, pouco menos de $10 \%$ (dez por cento) do total dos concluintes do Ensino Médio, naquele ano, inscreveram-se para o exame.

Continuando nessa perspectiva, longe estaria o ENEM de influenciar, de alguma forma, o Ensino Médio. Porém algo aconteceu entre o primeiro e o segundo Exame, indo, inclusive, de encontro às principais queixas dos alunos: a de que não havia motivos suficientes para a realização da prova já que a avaliação ficaria restrita ao sigilo individual, gerando somente resultados gerais ao sistema em sua totalidade.

A partir dos objetivos divulgados pelo INEP para o ENEM, percebia-se que o governo não desistiria facilmente de suas pretensões em relação ao exame, pois, mais do que a avaliação em si, estavam em disputa os rumos que essa modalidade de ensino deveria seguir.

Logo se intensificou a mobilização para que as universidades brasileiras incluíssem o ENEM no processo de seleção para o ingresso em seus cursos superiores. O próprio ministro Paulo Renato admitiu estar empenhado em que as universidades, principalmente as públicas, por terem maior credibilidade e por serem gratuitas, aceitassem incorporar os resultados do exame em seu processo seletivo $^{3}$. Começou daí a 'popularização' do ENEM. Segundo Maria Helena Guimarães de Castro, Presidente do INEP no governo FHC, a "adesão das instituições de ensino superior foi fundamental para fortalecer a credibilidade do Exame e contribuiu decididamente para transformá-lo numa nova referência na busca de alternativas aos processos seletivos tradicionais" (BRASIL, 2000, p.25). Assim, o ENEM deu um salto em número de inscritos.

Então, somado a outros fins, o ENEM passou a ser também critério de avaliação para a entrada em muitas universidades do país ${ }^{4}$. O número de inscritos sobe proporcionalmente ao número de universidades, preferencialmente

3 O jornal Folha de S. Paulo, de 17 de dezembro de 1998, traz o seguinte texto: "o ministro da Educação, Paulo Renato Souza, fez ontem um apelo às universidades para que o Enem (Exame Nacional do Ensino Médio) seja adotado como forma de acesso ao ensino superior".

4 Cada universidade decide a forma de aplicar o ENEM. A maioria estipula uma porcentagem de aproveitamento, que será somada a sua prova de conhecimentos gerais. 
públicas, que aderem ao processo, como anteviu o ministério ${ }^{5}$. Algumas universidades, como a Federal do Ceará, tornam o ENEM obrigatório para todos os que desejam fazer seu vestibular. Essa adesão compulsória - que gerou uma disputa judicial até às vésperas da realização das provas vestibulares da $\mathrm{UFC}^{6}$ - acaba por tornar o que era opcional em obrigatório de fato, pelo menos para aquela parcela da população que quer uma vaga na universidade, precisa dela e pode disputá-la.

O resultado não poderia ser outro. Os saltos em inscritos, como se vê no gráfico a seguir, são gigantescos.

QUADRO 1 - RELAÇÃO NÚMERO DE INSCRITOS X UNIVERSIDADES QUE ADEREM

AO ENEM

\begin{tabular}{|c|c|c|}
\hline ANO & N. $^{\circ}$ DE INSCRITOS & N. ${ }^{\circ}$ DE UNIVERSIDADES \\
\hline 1998 & 157221 & 02 \\
\hline 1999 & 347135 & 93 \\
\hline 2000 & 390574 & 137 \\
\hline 2001 & 1624131 & 211 \\
\hline 2002 & 1818665 & 327 \\
\hline 2003 & 1876387 & 409 \\
\hline 2004 & 1547094 & 436 \\
\hline
\end{tabular}

FONTE: Dados retirados do INEP

O governo fez a 'moda pegar'. Nos anos seguintes, uma multidão de concluintes, além dos já egressos, buscava a prova do ENEM; uma prova diferente da do vestibular, considerada mais fácil, mais interessante, de interpretação mais fácil, fugindo ao método da decoreba, como previu o ministro 7 . Várias escolas, muito mais as particulares do que as públicas, começaram a divulgar que seus conteúdos atendiam ao vestibular e ao ENEM. Surgiram, por outro lado, como uma febre, cursos preparatórios para o ENEM, 'cursinhos', os 'pré-enem',

5 A Folha de S. Paulo, em 17 de dezembro de 1998, cita a seguinte frase de Paulo Renato: "O Enem não pretende ser um sucedâneo do vestibular, mas um elemento de um novo processo seletivo. Se as universidades adotarem ou disserem que vão adotar o exame, o número de participantes explode no ano que vem, e é isso que a gente quer".

6 O incidente envolvendo o uso da nota do ENEM pelo vestibular da UFC, em 2002, deu-se quando o Ministério Público Federal, por intermédio do procurador Alessander Sales, entrou na justiça e conseguiu uma liminar suspendendo o uso da nota do ENEM. A UFC recorreu, conseguindo outra liminar que dava prosseguimento ao concurso. Por diversas vezes, a imprensa noticiou a suspensão do vestibular por conta de liminares.

7 Para uma comparação entre o desempenho dos alunos nas provas do ENEM e nas provas do vestibular, ver o trabalho de Pansanato e Soares (1999). 
sintoma de um sistema que vê a educação, a aprendizagem e o saber como mercadorias. Eles nem sequer atentaram que, se o discurso oficial no qual eles se baseavam para endeusar o ENEM estivesse correto, são incompatíveis os dois elementos; como água e óleo, o vestibular e o ENEM não se misturariam. Segundo Costa (2003), são duas propostas antagônicas; uma, baseada no acúmulo de conteúdos; a outra, no acúmulo de competências.

Agora já se pode perceber realmente como o ENEM foi se constituindo peça de interferência no Ensino Médio, como assinalou o ministro Paulo Renato. Para aqueles que não acreditavam no futuro do ENEM, que duvidavam da determinação do governo e de seus métodos, pouco a pouco foi ficando claro que todo o esforço para emplacar a avaliação estava surtindo o efeito esperado pelo MEC.

Aqui ressoam as palavras do ministro, quando insistia em categorizar o ENEM como auxiliar do professor em sala de aula. A questão que vem tomando forma refere-se à intenção do MEC de impor os pressupostos desse exame nacional à política curricular da educação básica brasileira. Só assim, nesse processo, vai se entendendo em que nível a sala de aula tem diretamente a ver com um exame geral de avaliação.

Mais uma vez, com referência ao estudo de COSTA (2003), tal intenção foi se verificando na prática desde o intenso trabalho político governamental de vinculação dessa avaliação nacional ao acesso às universidades públicas e privadas de todo o país, popularizando cada vez mais esse processo. Com essa popularização, tinha-se a intenção de levar adiante a ideia de substituir os vestibulares pelo ENEM, o que possibilitaria ao MEC/INEP determinar tacitamente os pressupostos curriculares da educação básica brasileira.

O ENEM, então, desde sua concepção, objetivava ser o instrumento que forjaria mudanças curriculares significativas no Ensino Médio. Não de acordo com os interesses particulares de seus mentores, mas dentro de uma concepção de um mundo em transformação, que exige do indivíduo novas habilidades e competências. Segundo Costa (2003, p.5),

a indução curricular promovida pelo ENEM, de acordo com os seus próprios pressupostos, desloca a ênfase da transmissão do conhecimento para o desenvolvimento de competências. Ou seja, um deslocamento epistemológico no objeto da atividade educativa. O que se propõe é superar uma realidade educacional em crise, supostamente causada pela concepção equivocada do conhecimento (disciplinar), associada a ela, estabelecendo em seu lugar o desenvolvimento de competências como "novo" eixo estruturante da ação educacional. 
O novo eixo estruturante para o Ensino Médio teria o ENEM como o principal instrumento de sua forjadura. Como, há muito tempo, a referência é o vestibular, inicia-se o processo de colocar o exame nacional em primeiro plano para corrigir e orientar os currículos das escolas médias. Criando novas demandas de conhecimento por meio da avaliação nacional, o governo induz uma transformação no vestibular, enquanto prepara sua abolição, tornando o ENEM seu natural sucessor.

Com essa perspectiva, o MEC entende que se aproxima de resolver o problema de parte do Ensino Médio, principalmente nas escolas particulares, sempre acusadas de estarem voltadas simplesmente para atender às exigências dos vestibulares, gerando um ensino dissociado da vida, pautado em fórmulas e conteúdos estanques, a maior parte deles desnecessária depois do vestibular.

Analisando, no entanto, algumas falas dos professores e diretores, durante as entrevistas que originou este estudo, outras questões podem estar surgindo no quadro da escola pública de Ensino Médio.

Eu, particularmente, defendo que os alunos participem do ENEM. O ENEM é um exame [...] que acaba sendo uma ponte entre a escola e o mundo lá fora. E o mundo está cobrando. A prova do ENEM está voltada para aquela aprendizagem que foge do conteúdo. Lá não pergunta o que é isso, o que é aquilo. Ele pega o conteúdo e aplica numa situação e você vai ver ai se o aluno aprendeu ou não. A percepção, a interpretação, o entendimento e o comportamento é que são avaliados. [...] Eu gosto do ENEM e gostaria muito que todos os alunos participassem, nesse sentido, de perceber no final dessa trajetória ou parte da trajetória educacional dele, o que eles conseguiram [aprender] no ensino médio. (Meiryvan)

O discurso do ENEM, como uma avaliação diferente do vestibular, que avalia sob outros aspectos, chegou até a sala de aula. Entretanto, corre o risco de cair na mesma dinâmica do vestibular. As falas seguintes confirmam essa assertiva:

Já utilizei provas que foram do ENEM, elaborando questões com os conteúdos parecidos com a dinâmica das provas do ENEM. A própria produção dissertativa do aluno, eu já trabalhei sistematicamente para o ENEM. Eu já tenho as provas que eu aplico dentro das minhas avaliações, eu tenho aquela prova do aluno dizer o que entendeu. Uso também a prova objetiva, porque é o que ele vai encontrar, também no ENEM, nos concursos, nos vestibulares. (Meiryvan) 
Trabalhei vários conteúdos direcionados para o ENEM. Desde que trabalho no Ensino Médio que tento preparar os alunos para fazer essa prova. A gente conversa com o aluno da importância, pega trabalhos, provas de ENEM, trabalha questões do ENEM passado, estuda o livrinho do ENEM, vê o que pode passar na próxima prova, o que pode cair na prova. Já preparei várias aulas direcionadas ao ENEM. Não que a direção exigisse, por minha própria iniciativa, por que a gente vê a propaganda, vê a possibilidade de o aluno chegar lá e dizer: 'eu posso, eu passo'; naquele intuito mesmo de ver meu aluno tentar conseguir alguma coisa, e medir [...] o seu potencial. (Norma)

Caso possa parecer que o ENEM esteja conseguindo direcionar o currículo do Ensino Médio, dada a preocupação dos professores em relação a esse aspecto, a preparação específica para a prova anula essa conquista, já que o princípio do ENEM é perceber habilidades e competências do aluno de forma geral. O treinamento para a realização da prova tira o caráter espontâneo de conhecimento adquirido e se transforma em um novo vestibular, com dicas, com 'bizus', com a aflição da concorrência.

Pelo depoimento que segue, fica demonstrado, pelo menos para o limite da realidade estudada aqui, que o professor recebeu o ENEM como um novo vestibular.

Eu não temo que a gente comece a preparar para o ENEM ao invés de preparar para o vestibular. Que substitua uma coisa pela outra. Eu acredito que seja uma soma. Na verdade eu não consigo separar: esse lado é [o] vestibular e esse aqui é [o] ENEM. Eu acredito assim: quando o aluno faz o ENEM, ele tem lá uma oportunidade de ver como é que está sua aprendizagem, [de] perceber as suas deficiências e, a partir daí, ele canaliza suas atenções para estudar os aspectos que considerou insatisfatório. $O$ vestibular também é necessário e, querendo ou não, o ENEM é um exame, acaba sendo um vestibular. Não vamos ser hipócritas: digamos que um [que] aluno temeu uma prova mínima no ENEM, ele vai está empolgado pra fazer vestibular? Não, porque vai ser o reflexo de como ele se sente, como está, na realidade, a sua aprendizagem em sala de aula. O ENEM, eu acredito, que apenas some na preparação para o vestibular. Pelo menos é esse meu discurso, é isso que eu defendo em sala de aula. (Meiryvan)

A linha de raciocínio da professora é bem coerente. Ela demonstra entender que o objetivo da escola é dar um sentido ao Ensino Médio. Para ela, esse 
sentido é propedêutico, de continuação dos estudos. Assim, parece-lhe certo fazer o que for possível para o aluno atingir a universidade. Se as universidades aderiram ao ENEM, a escola deve preparar o aluno para um bom desempenho na prova. Com uma avaliação considerada mais fácil do que o vestibular, o investimento nele é prioritário, pois, se o desempenho do aluno no ENEM não for satisfatório, dificilmente o será no vestibular. Com um bom desempenho no vestibular, vem a soma: soma de pontos para ingressar na universidade e soma de conhecimentos para a prova do vestibular. Sem hipocrisias, como defende a professora, o ENEM se transformou em um vestibular de segunda categoria, ou mesmo, um vestibular mais humanizado.

Dessa maneira, essa perspectiva do MEC - trazer o ENEM para orientar os currículos das escolas, indiretamente, pressionando via novas demandas de conhecimento, que serão exigidas nessa avaliação nacional - aproxima-se, e muito, da visão de transformar a educação em um grande cursinho. A diferença é que o cursinho anterior tinha o vestibular tradicional como alvo principal a atingir. Agora, o novo cursinho - quem quiser pode ler reforma do Ensino Médio - terá como objetivo os padrões do ENEM.

A máxima vem endossar que o problema não é o vestibular em si, mas sim, a não exigência de conteúdos compatíveis com a vida. Em outras palavras, passou-se muito a difundir que o problema não é seguir o vestibular. A questão é que o vestibular não estaria de acordo com o que a sociedade exige que o aluno aprenda. Como o vestibular, em nome da autonomia, depende de cada instituição de ensino superior, ele foi se fragmentando a ponto de cada escola exigir conteúdos diferentes, isolados. O ENEM, então, a nova bússola do Ensino Médio, entra para corrigir os currículos das escolas sem impor diretamente sua diretriz. É com essa conotação, como um modelo a ser seguido, que o ENEM tem a pretensão de servir como referência para os currículos.

Uma primeira questão é que o sistema educacional no Brasil, como em diversos outros países subdesenvolvidos ou ditos em desenvolvimento, é montado para deixar uma grande parte de fora. E a forma como o sistema funciona é a de um funil (os governos odeiam essa analogia). Mesmo quando estão dentro, como é o caso do Ensino Fundamental e, em menor grau, o do Ensino Médio, o baixo rendimento, a evasão e a repetência contribuem para alimentar o funil. Muitos entram, poucos saem (e os poucos têm sido, em sua grande maioria, os das classes dominantes). O funil alivia a pressão sobre os demais níveis. Do Ensino Médio para o Ensino Superior, isso é escancarado. Basta ver quantos concluem o Ensino Médio e quantos tentam acesso à universidade. E, dos que tentam o acesso, quantos conseguem entrar.

Assim, é preciso afirmar que o vestibular (o grande vilão) não existe para excluir, ele exclui para existir: é o instrumento que possibilita colocar uns para 
dentro e manter outros de fora. Por isso que é ingênuo o MSU (Movimento dos Sem Universidade), anteriormente acordado com a direção do evento, invadir a fala do ministro da Educação, pedindo o fim do vestibular ${ }^{8}$. A verdade é que não há vagas para quem não pode pagar (sejam as universidades ou as escolas básicas). É a exclusão que faz existir o vestibular. Ele se faz necessário pela função que o Brasil ocupa na atual ordem capitalista. A prioridade da política econômica é o pagamento das dívidas internas e externas, do investimento no agronegócio, do sucateamento da educação pública, das privatizações das estatais. É inerente ao sistema educacional do capitalismo subdesenvolvido a exclusão. Isso não quer dizer que se deve cruzar os braços e não fazer nada, "pois tudo já está resolvido" ou "nada pode ser feito". Pelo contrário. Só mostra que nada está resolvido, que o trabalho de quem quer construir uma sociedade diferente é muito mais complexo do que as reformas, no sistema capitalista, podem sugerir.

Diante de todo o exposto, fica evidente que o ENEM cresceu em cima do desejo/ilusão de milhões de jovens de ingressar no ensino superior após as universidades 'aceitarem' usar o resultado como parte de seu processo seletivo. Com o uso desse imaginário, o MEC pensa em consolidar o exame para transformá-lo em bússola para a reforma do Ensino Médio (contribuindo com o professor em sala de aula), para acabar com o currículo para a 'não-vida' e efetivar o novo currículo para a vida.

Não precisa ser nenhum vidente para imaginar o estrago que isso vai causar. De fato, o exame só atinge mesmo uma minoria que está na ponta do funil tentando escapar para a universidade. Desses, as estatísticas denunciam, todos os anos, só uma pequena parte vai conseguir sentar-se nos bancos dos institutos superiores de ensino. A grande massa que fez a inscrição para o ENEM foi ludibriada pela intensa propaganda de que poderia ser aprovada no vestibular se tivesse um bom desempenho. A onda de crescimento tanto já parou como já começou o recuo de inscritos no ENEM (basta ver os anos de 2002, 2003 e 2004 do quadro VII). A tendência é estabilização nos marcos dos mesmos números dos vestibulares. Quem vai pagar o preço pelo patrocínio gratuito da frustração em nossos jovens não se sabe, mas a história deve dar alguma resposta, alhures.

Portanto, achar que uma avaliação que já nasce com a função de selecionar pode contribuir com o professor para construir um novo Ensino Médio, demonstra bem que tipo de reforma se pretende implantar: além de estar baseada no currículo, ainda depende sobremaneira da ilusão de acesso ao Ensino Superior, que dura pouco tempo.

8 Aconteceu no Fórum Mundial de Educação em São Paulo, durante a palestra proferida pelo atual ministro da Educação, Tarso Genro. 


\section{REFERÊNCIAS}

BRASIL. Ministério de Educação/Secretaria de Educação Média e Tecnológica. Parâmetros curriculares nacionais: ensino médio. Brasília, MEC/SEMTEC, 1999.

BRASIL. Exame Nacional do Ensino Médio: relatório final 1999. Brasília: Inep, 2000. COSTA, Cláudio Fernandes. O ENEM e o desenvolvimento de competências no contexto da educação para o trabalho e a cidadania. Rio de Janeiro, Teias, 2003.

ENEM e o vestibular. A Folha de S. Paulo, 17 dez. 1998.

MEC prevê fim do vestibular. Jornal Folha de S. Paulo, 5 jul. 1997.

MINISTRO faz apelo às universidades. Jornal Folha de S. Paulo, 17 dez. 1998.

PANSANATO, Kleber Adriano; SOARES, José Francisco. Desempenho dos alunos no ENEM e no vestibular da UFMG. En publicacion, São Carlos(SP), Brasil, 1999.

SANTOS, Jean Mac Cole Tavares. O ensino médio no interior cearense sob os impactos da reforma: entre o discurso oficial do novo mundo do trabalho e as apropriações/ resistências pela escola (1995-2005). Tese (Doutorado) - UFPB, João Pessoa, Pb, 2007.

TÓFOLI, Daniela. Exame nacional vira referência. Jornal Folha de S. Paulo, 05 jul. 2007.

Texto recebido em 07 de novembro de 2009.

Texto aprovado em 16 de julho de 2010. 
